\title{
SENSOR AND CLOUD BASED SMART IRRIGATION SYSTEM WITH ARDUINO: A TECHNICAL REVIEW
}

\author{
Janak Patel \\ Student \\ Department of CSE \\ Parul Institute of Technology \\ Parul University, Vadodara, Gujarat, \\ India
}

\begin{abstract}
Agriculture plays very important role in Indian economy.Due to scarcity of water in many villages of india, $50 \%$ of this water is wasted due to overwatering caused by inefficiencies in traditional irrigation methods and systems. It is harmful for plants and also for soil. Motivation came from the countries where economy is based on agriculture and the climatic conditions lead to lack of rains \& scarcity of water. Irrigation is one of the method to supply water but in some cases, there will be lot of water wastage. The farmers working in the farm lands are purely dependent on the rains and bore wells for irrigation of the land. Even if the farm land has a water-pump, manual intervention by farmers is needed to turn the pump on/off whenever required. The aim of our project is to minimize this manual intervention by the farmer, 1) To develop a wireless controlled smart irrigation system using IOT which detects soil moisture and accordingly water the crops. This saves water, electricity and human efforts. Also maintains fertility of the land. 2) The irrigation is done only when there is not enough moisture in the soil and the threshold value decides when the pump should be turned on/off, saves a lot time for the farmers. According to data obtained from sensor, Cloud platform will on/off water motor as per the decided threshold value. This is a complete automated where devices communicate among themselves and apply the intelligence in irrigating. This can be developed using low cost embedded devices like Arduino Uno.
\end{abstract}

Keywords - Internet Of things, Cloud computing, Data Analysis.

\section{INTRODUCTION}

Agriculture has wide impact on indian economy and it is the backbone of indian economy. In today's world we see rapid growth in global population. Agriculture become most important to meet needs of human race. However it requires irrigation and with each year we have more water consumption than rainfall. As rainfall is becoming irregular in India with each passing year. Therefore it becomes critical for growers to find ways to conserve water. Due to scarcity of water fertility of soil reduces to much extent. Same for overwatering as some areas have more than sufficient water for irrigation. Also problem of electricity in some areas like small villages remains constant. Many areas receive in time laps like at night. To solve all above mentioned problems we have introduced smart irrigation system which water the plants according to its need. No manual intervention is required and everything is done automatically. Motive is to reduce usage of water and electricity and also human efforts. By using internet technologies and sensor network technology we can control water wastage and to maximize scientific technologies in irrigation methods. Hence it can greatly improve the utilization of water and can increase water productivity. This will be done through measuring soil moisture and acting accordingly. We will be using Arduino Uno board, soil moisture sensor, ESP8266 module, Thingspeak cloud platform. In short we will be using IoT for automation. The Internet of Things (Iot) is a technology where in a mobile devices can be used to monitor function of device. IoT is concerned with intercommunication objects that are possibly distant from each other. It is a type of network technology, which senses information from different sensors and making anything to join internet to exchange information. Soil moisture sensor will sense moisture level of the soil and according to the decided threshold value it will water the crops automatically. This will be done using a higher communication device such as wifi module. The data processed by central module is coverted to meaningful data and relayed to user. User can view data with help of handheld devices such as mobile phone or tablet. This project helps farmers to irrigate farmland in efficient manner with automated irrigation system based on soil moisture. The proposed system has been designed to overcome unnecessary water flow into agriculture lands. 


\section{International Journal of Engineering Applied Sciences and Technology, 2019 Vol. 3, Issue 11, ISSN No. 2455-2143, Pages 25-29 \\ Published Online March 2019 in IJEAST (http://www.ijeast.com)}

\section{OBSERVATION}

In this chapter, We have given my critical evaluation \& summary of all research papers that I read related to my project. For existing systems advantages and disadvantages are mentioned below.

\section{GSM based system ${ }^{[1]}$}

He describe the problem of population increase and with it arising problem of food. Also water scarcity is major issues farmers are suffering from. Main motive of Karan Kansara is to provide an automatic irrigation system thereby saving time, money and power of the farmer. He was described reasons for automatic irrigation system as it is simple to install and configure. It saves energy and resources, so that it can be utilized in proper way and amount. It saves time and human error limitation in adjusting available soil moisture levels and many more. It uses GSM based automatic irrigation control system for efficient use of resources and crop planning by using an android phone.

Start process - initialize power is supplied to GSM - check moisture level - If the level less - start irrigation - stop the process. Advantages of this system is it saves water and time. But Disadvantage is it is just limited to automation of irrigation system and lacks in extra ordinary feature

\section{Solenoid valve controlling system ${ }^{[2]}$}

He explains the problem of mater scarcity in farming. This project presented by him helps farmer to irrigate the farm land in an efficient manner with automated irrigation system on soil humidity. Humidity sensor will be used to find soil humidity and based on this microcontroller drives solenoid valve. Irrigation status will be updated to the server or local host using personal computer. Java platform will be used for getting information via serial communication from microcontroller and update in the server. In addition for better cropping system, fertilizer required for the crops, best crops to conducted for particular climatic as soil conditions are updated to server at regular basis by monitoring soil $\mathrm{PH}$ level, temperature level of field area etc. By using PC host, crop will be continuously monitored. From his project he concludes that irrigation process is done better than before to yeild proper production. Usage of water level is limited how much that system weds. Due to server updates farmers can know about crop field nature and everything at anywhere.

\section{Arduino and raspberry pi driven ${ }^{[3]}$}

This paper proposes a design for automatic water supplying system in farmland using rasberry pi 3, Arduino microcontrollers, Wifi module, GSM shield, relay boards and couple of sensor. The components we use in our system ensure overall fecund, scalable and spirited implementation depending upon the moisture level of farmland and daylight intensity, the system can detect the appropriate time of water supply in trees and can also keep track of water levels to prevent water from being accumulated around roots of saplings. The analog data received from sensor area transmitted by Arduino as digital single via Wifi module to Raspberry pi 3 . The system is able to modify the admin is track and can also communicate with the system by sending SMS of a particular keyword. This system can be applied in farmland as well as in small pot plants. Using this system, a very promising outcome is found in sustaining and cherising the plants in more scientific way. After assembling the system, the readings of sensor has been checked. They have tested system response in different situations.

\section{Data Collection with Wireless Sensor Networks ${ }^{[4]}$}

Saiyan Saiyed and Nattapol Kaewmard says that feeding of the world in $21^{\text {st }}$ century is the biggest challenge, especially for smart farm business. The farm has been used agriculture automation system instead of traditional agriculture. Their research goal is to provide long term sustainable solution for automation of agriculture. Therefor they developed a portable measurement technology including soil moisture sensor, air humidity sensor and air temperature sensor, with the purpose for collecting the environment data and controlling the irrigation system via smart phone. Purpose of this experiment is to find better ways of controlling and irrigation system with automatic system and manual control by smart phone. In order to control an irrigation system, they have developed the communication methodology of wireless sensor network for collected environment data and sending control command to turn on/off irrigation system. The experimental results shows accuracy of sending and receiving command control for irrigation is $96 \%$ and accuracy of sending and receiving command control for environment collection is $98 \%$. Watering volume is a little faulty which is sometimes caused by overwatering. The error related to many factors such as rain, soil type and specification of vegetable crops.

\section{Threshold value decision based on environmental condition $^{[5]}$}

Sheetal Vatari, Aarti Bakshi and Tanvi Thakur says that there are many techniques available for the precision agriculture to monitor and control, environment for the growth of many crops. Due to unequal distribution of rain water, It is very difficult to requirement needed farmer to manage water equally to all the crops in whole farm it requires some irrigation method that suitable for any weather conditions, soil types and variety of crops. They say that green house is the best solution to control and 


\section{International Journal of Engineering Applied Sciences and Technology, 2019 Vol. 3, Issue 11, ISSN No. 2455-2143, Pages 25-29 \\ Published Online March 2019 in IJEAST (http://www.ijeast.com)}

manage all this problem. It is more important to search a method that gives perfect analyzation and controlling to develop proper environment large areas covered by sensor network this can be established green house with precision environment required for crops. This environment builds up by using the technologies it and could computing. By using Internet of things we control devices or any environmental needs anytime, anywhere cloud which provides storage and computing resources to implement a webpage. They say one of the most challenging problem is due to unequal distribution of rain water. To solve this problem they have designed an algorithm which will determine present environmental conditions. According to requirement of the crops threshold will be set, if it goes below threshold value, be set, if it goes below threshold value then IoT its sense the changing in parameters are monitored simultaneously and all data will be transmitted to farmers, according to that farmer will take decision and send to system. IoT and cloud computing makes a system IoT and cloud computing makes a system that controls greenhouse effectively. This asset allows cultivation in a way plants need. It leads to higher crop yield. Prolonged production period, better quality and less use of productive chemicals.

\section{Xbel modules operation ${ }^{[6]}$}

Nikhil Agrawal and Smita Singhal proposes a design for home automation system using ready to use ,cost effective and energy efficient devices including raspberry $\mathrm{Pi}$, arduino microcontrollers, Xbel modules and relay boards use of these components results in overall cost effective, scalable and robust implementation of system. The commands from the use are processed at raspberry $\mathrm{Pi}$ using python programming language. Arduino micro controllers are used to receive on/off command from raspberry pi using zigbee protocol star zigbee topology serves as backbone for communication between raspberry pi and end device. Raspberry pi acts as central coordinator and end device act as various routers. Low cost and energy efficient drip immigration system serves as proof of concept. This design can be used in big agriculture fields as well as in small gardens via just sending an email to system to water plants. This paper explain complete installation of the system including hardware and software aspects.

\section{Zigbee communication $^{[7]}$}

The main intention is to develop an automation to supply water for home gardening and irrigation system in farm fileds. It is done with help of soil moisture sensor and temperature sensor which are fixed at root area of plants. The valves detected by these sensors are transmitted to base station. The key aim of base station is to collect data from filed station and upload those values in internet by using Wifi technology also notify user about any peculiar circumstances like low moisture and high temperature.
They states that their method has been approved under different climates with various levels of moisture contents especially red chilly weeds. Home gardening is the hobby of many people and also same work for irrigation system in agriculture fields, is the application of this system. The values are displayed which are received from sensing unit and transmitted via ZigBee module received values are compared with set-point Wifi module (ESP8266) which is interfaced to the microcontroller uploads the noted values of temperature \& soil moisture in web from zigbee receiver values are received at personal computer using visual basic the graphs are plotted for temperature and moisture with respect to time. Results of this system is the automation in irrigation system applied was on a located to be appropriate and price adequate for accessing water source of supply for agriculture management. This method permits farming in areas with water scarcity thereby making improvements to hold water.

\section{Autonomous system using Raspberry $\mathbf{P i}^{[8]}$}

In this paper Josephat Kalezhi particularly focus on some rural areas in South Africa \& Zambia which faces a number of similar issues in domains of agriculture, connectivity, water transport, health \& education etc which calls for potentially similar solutions to be directed toward solving these issues. The intention of this research is to investigate the potential contributions of Internet of things $(70+)$ towards poverty reduction in these rural areas, in line with the needs identified in these communities and with emphasis on agriculture. This paper identifies example of IOTs to mitigate and agricultural needs of these communities for the domain of crop farming, weather, forecasting, wildling management etc. The uses weather forecasting as main domain for his paper. It can be done through analysis of weather data over long periods to reduce agriculture risk. This is refered to as big data analysis. In weather forecasting for pest management, humidity, precipitation, crop type etc. are collected at local level through sensors. Life cycle of pests is monitored along with climate data The purpose of this research is to identify and gain an understanding of needs of SA and zambian ruler area and what intervention can be provided in terms of $70 \mathrm{~T}$ application of IOT in agriculture for suitable rural development.

\section{Wireless sensors and data monitoring ${ }^{[9]}$}

In this paper, Prof. Rashmi Jain along with Shaunak Kulkarni, Ahtesham Shaikh and Akash Sood have described the importance of agriculture and food production. They say that in our country, agriculture are depends on the monsoons which is not sufficient source of water. So the irrigation is used in agriculture field. In Irrigation system, depending upon the soil type, water is provided to plant. The greenhouse based modern 


\section{International Journal of Engineering Applied Sciences and Technology, 2019 Vol. 3, Issue 11, ISSN No. 2455-2143, Pages 25-29 \\ Published Online March 2019 in IJEAST (http://www.ijeast.com)}

agriculture industries are the recent requirement in every part of agriculture in India. In this technology, the humidity and temperature of plants are precisely controlled. Due to the variable atmospheric circumstances these conditions sometimes may vary from place to place in large farmhouse, which makes very difficult to maintain the uniformity at all the places in the farmhouse manually. It is observed that for the first time an android phone-control the Irrigation system, which could give the facilities of maintaining uniform environmental conditions are proposed. The main objective of the present paper is to develop a smart wireless sensor network (WSN) for an agricultural environment. Monitoring agricultural environment for various factors such as soil moisture, temperature and humidity along with other factors can be of significance. A traditional approach to measure these factors in an agricultural environment meant individuals manually taking measurements and checking them at various times. This paper investigates a remote monitoring system using RF module. These nodes send data wirelessly to a central server, which collects the data, stores it and will allow it to be analyzed then displayed as needed and can also be sent to the client mobile.

\section{Manual control system using Arduino for ON/OFF the water pump $^{[10]}$}

In this paper they say that agriculture is the most important occupation for the most of the Indian families. It plays vital role in the development of agricultural country. In India, agriculture contributes about $16 \%$ of total GDP and $10 \%$ of total exports. Water is main resource for Agriculture. Irrigation is one method to supply water but in some cases, there will be lot of water wastage. Therefore, in this regard to save water and time we have proposed project titled Arduino based automatic irrigation system using IoT. In this proposed system, we are using various sensors like temperature, humidity, soil moisture sensors that sense the various parameters of the soil. In addition, based on soil moisture value land is automatically irrigated by ON/OFF of the motor. These sensed parameters and motor status will be displayed on user android application. The Internet of Things (IoT) is a technology where in a mobile device can be used to monitor the function of a device. The Internet of Things (IoT) is concerned with interconnecting communicating objects that are installed at different locations that are possibly distant from each other. Internet of Things (IoT) is a type of network technology, which senses the information from different sensors and make anything to join the Internet to exchange information.

The main objective of this project is to provide an automatic irrigation system thereby saving time, money \& power of the farmer. The traditional farm-land irrigation techniques require manual intervention. With the automated technology of irrigation the human intervention can be minimized.

The application of agriculture networking technology is need of the modern agricultural development, but also an important symbol of the future level of agricultural development. With more advancement in the field of IoT expected in the coming years, these systems can be more efficient, much faster and less costlier. In the Future, this system can be made as an intelligent system, where in the system predicts user actions, rainfall pattern, time to harvest and many more features which will make the system independent of human operation.

Each of these system has their own unique features and on comparison to one another lacks some advancement. Apart from the actual projects we consulted, we also did some research on the background of this field, we went in north gujarat and studied about drip irrigation system that they uses in their farming land to water the plants, we also asked what is the methodology about automation of watering plants.

By referring all above papers it is found that no such systems are existed with all integrated features but proposed system includes these all features such as displaying water usage, electricity usage and soil moisture values and also automatic switching on and off of motor by considering soil moisture values.

\section{PROPOSED METHODOLOGY}

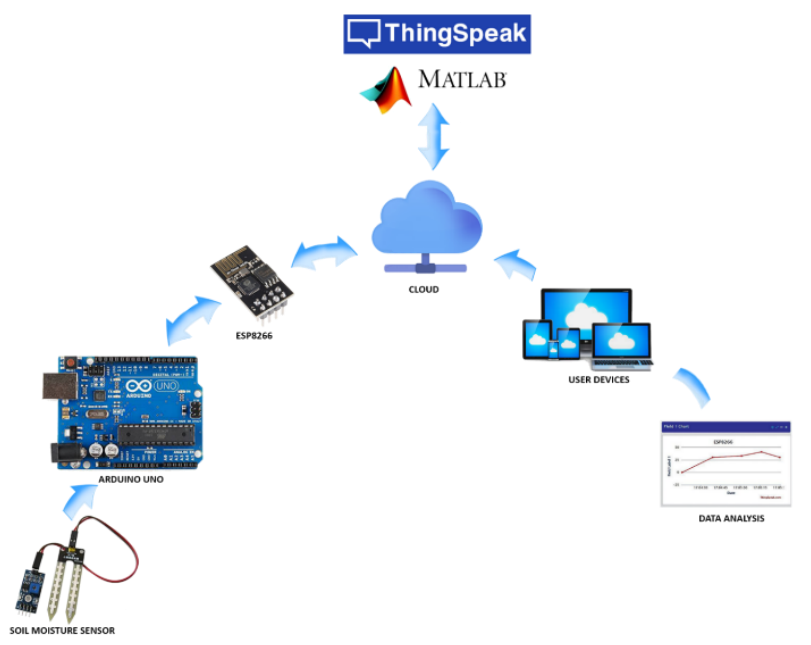

Fig.1 Proposed Methodology

Figure 1 shows overall flow of the system. Arduino based irrigation system which consists of sensors which are connected to controles and sensed values from sensor are send to Arduino which processes the data and are analysed by Thingspeak cloud platform. ESP8266 module helps to connect this through internet connectivity. 


\section{International Journal of Engineering Applied Sciences and Technology, 2019 \\ Vol. 3, Issue 11, ISSN No. 2455-2143, Pages 25-29 \\ Published Online March 2019 in IJEAST (http://www.ijeast.com)}

Figure shows block diagram of smart irrigation system with IoT. This proposed work includes an embedded system form automatic control of irrigation. It has wireless sensor network for real time sensing of irrigation system. This system provides uniform level of water for agricultural farm and avoids wastage of water when moisture level in soil reaches below threshold value then system automatically switches $\mathrm{ON}$ the motor. When it reaches normal level it automatically switches OFF current status of the system will be displayed in user's android application.

\section{CONCLUSION}

The automatic irrigation system described can ensure systematic and scientific approach in taking care of plants which can improve productivity. Such a system can easily be made and is not very costly. With the improvement of sensor technology, system will become more efficient and useful. For instance, values obtained from sensor can help in supplying sufficient amount of water and reducing water wastage. This system will sense all environmental parameters and send that data to the user via cloud. This asset allows the farmer to improve the cultivation in a way the plants need. It leads to higher crop yield, prolonged production period, better quality, and less use of protective chemicals. Electricity used in supplying water is also saved in this system. Mainly human efforts are reduced to much extent. This approach of smart irrigation system will lead agriculture in the world of automation and machines.

\section{REFERENCES}

[1] Karan Kansara, Vishal Zaveri, Shreyans Shah, Sandip Delwadkar, Kaushal Jani, 2015 "Sensor based Automated Irrigation System with IOT: A Technical Review," IJCSIT, 5331-5333.

[2] G. Parameswaran, K.Sivaprasath, 2016, "Arduino Based Smart Drip Irrigation System Using Internet of Things," IJESC, 5518-5521.
[3] Nomusa Dlodlo, Josephat Kalezhi, 2015, “The Internet of Things in Agriculture for Sustainable Rural Development", IEEE, 13-18.

[4] Nattapol Kaewmard, Saiyan Saiyod, 2014, "Sensor Data Collection and Irrigation Control on Vegetable Crop Using Smart Phone and Wireless Sensor Networks for Smart Farm," IEEE Conference on Wireless Sensors (ICWiSE), 106-112.

[5] Sheetal Vatari, Aarti Bakshi, Tanvi Thakur, 2016, "Green House by using IOT and Cloud computing," IEEE, 246-250.

[6] Nikhil Agrawal, Smita Singhal, 2015, "Smart Drip Irrigation System using Raspberry pi and Arduino," International Conference on Computing, Communication and Automation (ICCCA),928-932.

[7] M. Kranthi Kumar, K. Srenivasa Ravi, 2016 "Automation of Irrigation System based on Wi-Fi Technology and IOT," Indian Journal of Science and Technology, DOI- 10.17485/ijst/2016/v9i17/93048.

[8] Ahmed Imteaj, Tanveer Rahman, Muhammad Kamrul Hossain, Saika Zaman, 2016 "IoT based Autonomous Percipient Irrigation System using Raspberry Pi," 19th International Conference on Computer and Information Technology, 563-568.

[9] Prof. Rashmi Jain, Shaunak Kulkarni, Ahtesham Shaikh, Akash Sood, 2016, "AUTOMATIC IRRIGATION SYSTEM FOR AGRICULTURE FIELD USING WIRELESS SENSOR NETWORK (WSN)," International Research Journal of Engineering and Technology (IRJET), 1602-1605.

[10] Pavankumar Naik, Arun Kumbi, Vishwanath Hiregoudar, Chaitra N K, Pavitra H K, Sushma B S, Sushmita J H , Praveen Kuntanahal, 2017 "Arduino Based Automatic Irrigation System Using IoT," International Journal of Scientific Research in Computer Science, Engineering and Information Technology, 881-886. 